\title{
From design towards manufacturing of winglets with integrated VHF antenna
}

\section{EMUS 2019}

\author{
KAI GONET ${ }^{*}$, STEFAN STEEGER ${ }^{*}$, ZDENĚK ŘEZNÍČEK ${ }^{\dagger}$ MARTA MARTÍNEZ- \\ VÁZQUEZ $^{\dagger \dagger}$, JORDI BALCELLS-VENTURA ${ }^{\dagger \dagger}$, PETR VRCHOTA ${ }^{\dagger \dagger \dagger}$, VICTOR \\ LUNGAHO ${ }^{\dagger+\dagger \dagger}$ \\ *INVENT GmbH \\ 38112 Braunschweig, Germany \\ e-mail: kai.gonet@invent-gmbh.de, http://www.invent-gmbh.de
}

${ }^{\dagger}$ Evektor

686 04, Kunovice, Czech Republic

e-mail: engineering@evektor.cz,www.evektor.cz

† IMST GmbH

47475 Kamp-Lintfort, Germany, email: contact@imst.com,www.imst.com

it广 VZLU - Czech Aerospace Research Centre 19905 Prague, Czech Republic

e-mail: vrchota@vzlu.cz, web page: http://www.vzlu.cz

†i† Trackwise

Gloucestershire GL20 8NB

United Kingdom

e-mail: victor.lungaho@trackwise.co.uk -web page: www.trackwise.co.uk

Key words: Integral Construction, Notch Antenna, Winglet, Aviation Engineering

Abstract. This paper shows the technical aspects and the progress of manufacturing a winglet concept with integrated VHF antenna.

\section{INTRODUCTION}

Reducing fuel burn emissions is one of the most important aims in aircraft design nowadays. One possibility for reducing the aerodynamic drag of airplanes is to reduce the number of protruding parts as antennas. One possible design concept is to move the antenna within the winglet and to integrate the transceiver of electromagnetic radiation into the aerodynamically optimized structure [1]. The challenge of this goal is to build the VHF antenna with its wavelength defined size into a winglet. The winglet designed in ACASIAS is for a small transport aircraft of the type Evektor EV55. This small size makes the integration in the small installation space a demanding task. This construction method shown here can also be easily used on larger aircraft. Another challenge of the design process is that the 
Kai Gonet, Stefan Steeger, Zdeněk Řezníček, Marta Martínez-Vásquez, Jordi Balcells-Ventura, Petr Vrchota, Victor Lungaho

winglet must be certifiable, maintainable, and repairable at the final stage for all systems and structure.

\section{WINGLET DESIGN}

Neither a high-quality winglet nor a VHF antenna is a revolutionary new idea. In aviation, however, assemblies are usually separated according to their function. Functional integration is unusual. In this chapter the structural design and the necessary boundary conditions will be discussed.

Several aspects of the winglet design have to be considered. First of all, it should apply the aerodynamically optimized shape for reducing the vortex drag at the tip of the wing, as well as it should fulfill the structural need for inducing aerodynamic forces and moments to the wing, remain stable in the event of bird strikes, and it should resist lightning strikes. The integrated antenna should be able to transmit VHF (very high frequency) radio communication to and from other air or ground stations.

Therefore, it is inevitable that the signals from the integrated antenna within the CFRP structure (Carbon Fiber Reinforced Plastic) are erased by a GFRP (Glass Fiber Reinforced Structure) "window" inside the winglet. CFRP does not allow electromagnetic radiation to pass through. The boundary conditions for an antenna is summarized in [2] and [3].
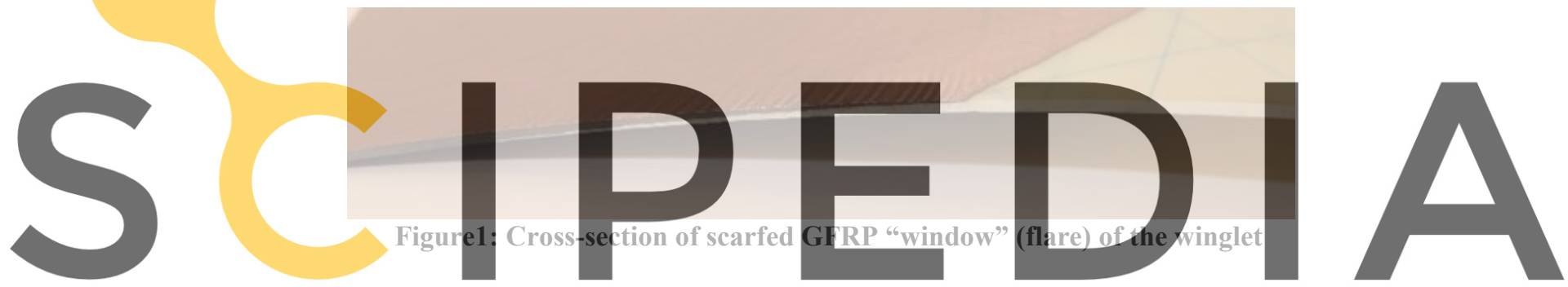

The notch antenna design itself was delivered by IMST, which is responsible for this topic.

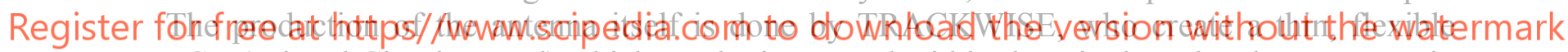
PCB (Printed Circuit Board) which can be integrated within the winglet. The electromagnetic design is given in [4].

The position of the notch fiberglass antenna and "window" is very important for the reception and transmission of high frequency data.
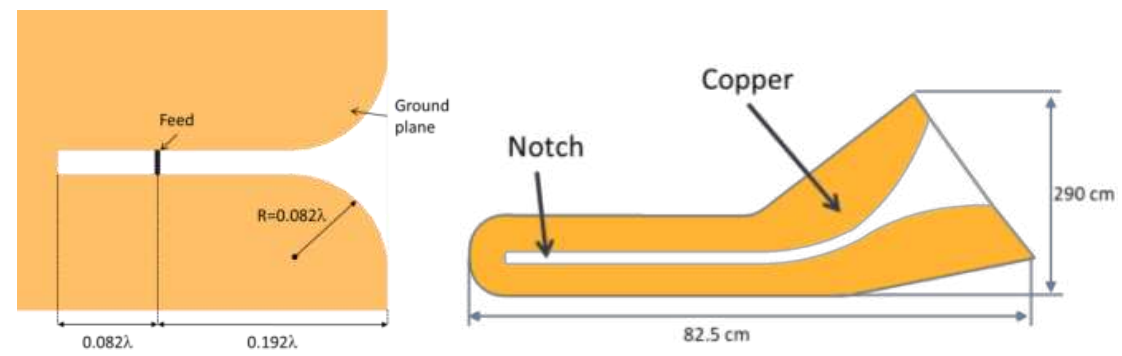

Figure2: Notch antenna. Left: Basic structure, Right: final geometry

\subsection{Aerodynamic optimization}

As mentioned, the Evektor EV55 is used for the EU project ACASIAS for the design. This aircraft was examined and optimized by VZLU under the aerodynamic conditions of the flight 
Kai Gonet, Stefan Steeger, Zdeněk Řezníček, Marta Martínez-Vásquez, Jordi Balcells-Ventura, Petr Vrchota, Victor Lungaho

envelope. The core of the optimization is the reduction of drag and the reduction of the number of attachments promoting drag. Two Evektor EV55 aircrafts are flying at the time of this study.

The optimization strategy is based on the Design of Experiment (DoE). The Response Surface Method (RSM) is also used. More detailed descriptions can be found in [5]. The optimization resulted in a winglet shape with the highest reduction of induced drag. The result is the yellow winglet shorn in Figure 3.

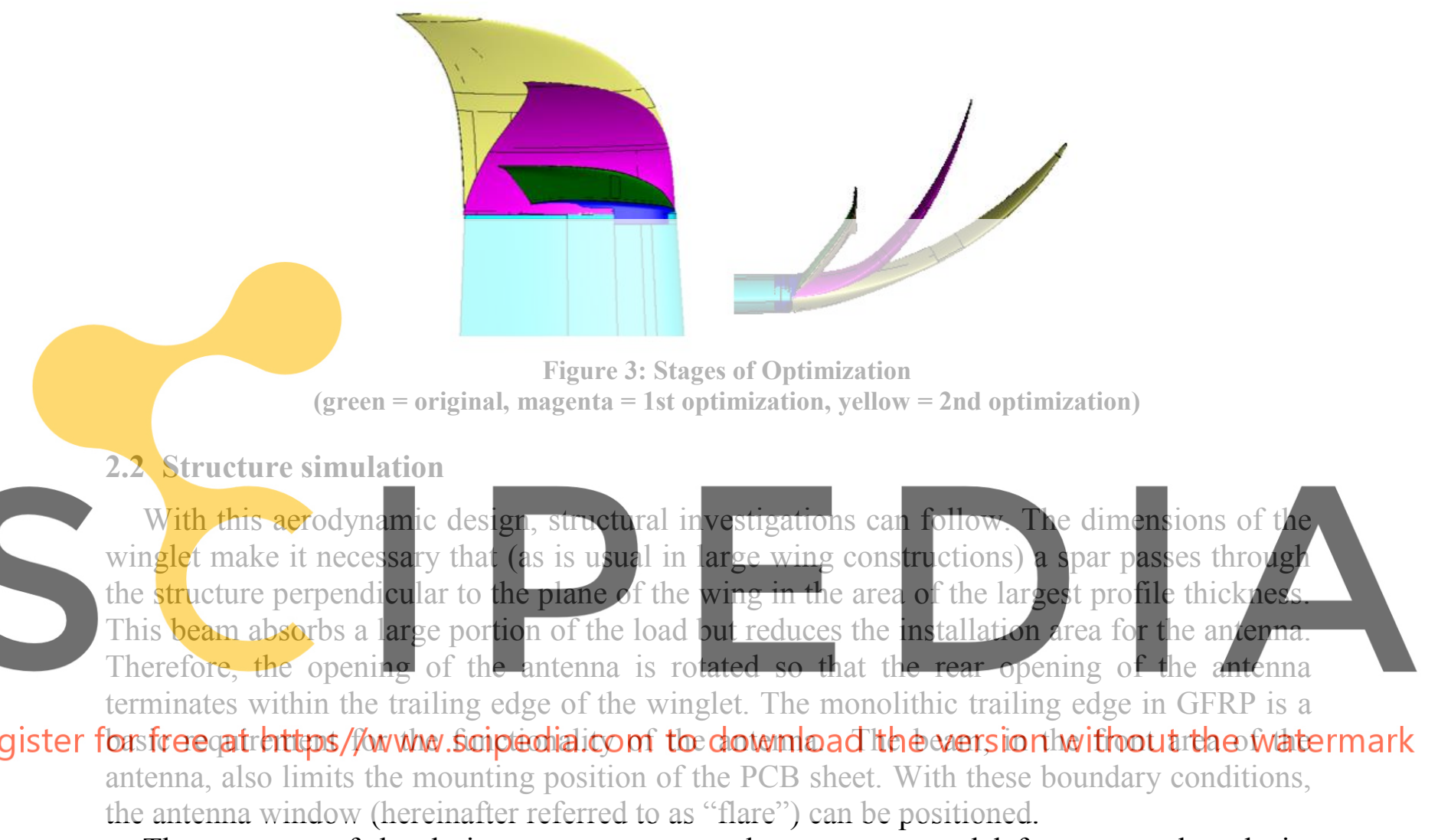

The structure of the design concept was used to create a model for structural analysis. Before the structural investigation can be performed, the antenna notch must be positioned.

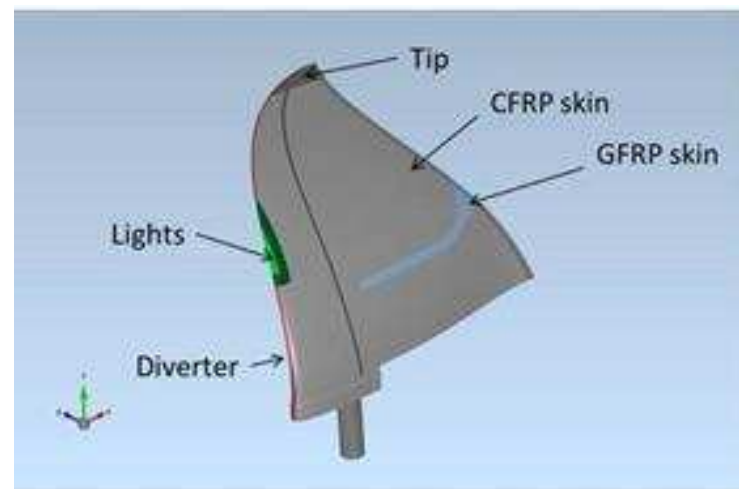

Figure: 4: Structure of winglet with notch antenna and the "flare" window 
Kai Gonet, Stefan Steeger, Zdeněk Řezníček, Marta Martínez-Vásquez, Jordi Balcells-Ventura, Petr Vrchota, Victor Lungaho

The stress on the winglet is calculated using the pressure distribution. In fact, the ultimate load factor must be taken into account. The winglet itself is made out of CFRP with a scarfed GFRP flare with dielectric properties for VHF antenna operation. The core of the winglet consists of a spar and a structural foam. The critical load case was considered by VZLU and EVEKTOR for an AoA of $17^{\circ}$. INVENT placed the pressure field (delivered by VZLU) on the structural model of the winglet. The ultimate load as a safety factor for individual parts were determined as followed:

- $\quad$ x 2.25 for composite parts

- $\quad$ x 1.5 for metallic components

The pressure distribution was also multiplied by this safety factor, as well as the acceleration due to gravity. The pressure distribution was projected onto the wetted winglet surface. The first structural model was based on a CFRP material thickness of $2.5 \mathrm{~mm}$, which corresponds to a plybook of 10 layers for the outer skin. The first estimation of material and thickness provided a total weight of $11.5 \mathrm{~kg}$.

The first iterations with the $11.5 \mathrm{~kg}$ model showed that the winglet is far stronger than required. This led to weight optimization. In several successive steps, the influence of the reduction in material thickness and density was determined under the specific load. The structurally optimized winglet is a design with a lightweight foam core. The spar thickness is reduced. The material thickness of the outer skin was also reduced from $2.5 \mathrm{~mm}$ to $1.7 \mathrm{~mm}$ (corresponding to 7 layers). $2 \mathrm{~mm}$ CFRP is applied only in the winglet root area. The final weight is around $8.5 \mathrm{~kg}$.

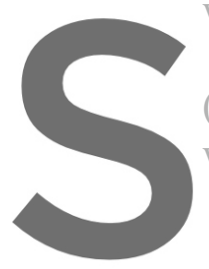

In the following the (right) of the winglet is which has little influence
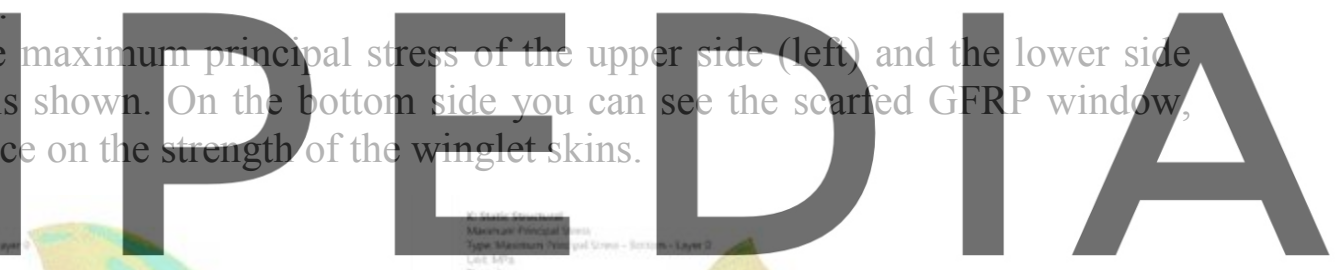

Register for free at https//www.scipedia.com to download the version without the watermark
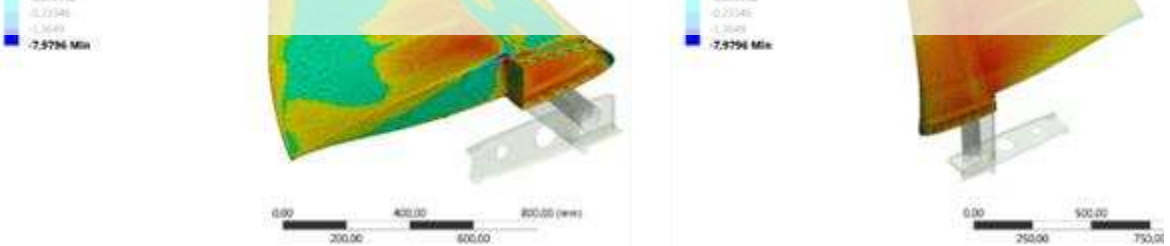

Figure 5: Maximum principal stress in logarithmic scale (Left: top side, Right: bottom side)

Within the optimization process the structure model could be further refined. For the calculation an Inverse Reserve Factor (IRF) with Tsai-Wu failure criteria was used. If the value of the IRF is less than one, there is no damage to the fiber composite structure.

The resulting IRF composite is 0.29 (usual: IRF $=1=$ Failure). According to ultimate load.

$\operatorname{IRF} /($ ultimate load $)=\mathbf{1} /(\mathbf{2} . \mathbf{2 5})=0.57$

is below IRF $=1$. Therefore, the winglet structure is safe.

The support reaction that are transferred into the wing was also calculated. For EVEKTOR these values are essential for the design of the wing itself. These values were delivered for redimensioning the wing spars and stringers. 
Kai Gonet, Stefan Steeger, Zdeněk Řezníček, Marta Martínez-Vásquez, Jordi Balcells-Ventura, Petr Vrchota, Victor Lungaho

Bird strike is also considered. The highest risk of a bird strike is the displacement of the trailing edge inwards towards the aileron. In the event of a bird strike, the winglet must not block the aileron. For cruising speed of $400 \mathrm{~km} / \mathrm{h}$ and a bird weight of $2 \mathrm{~kg}$ the reaction force on the wing via the impact energy and the impulse were calculated. The calculation of this force applied to the outermost part of the structure results in a displacement of the trailing edge of $4 \mathrm{~mm}$. This displacement does not affect the aileron

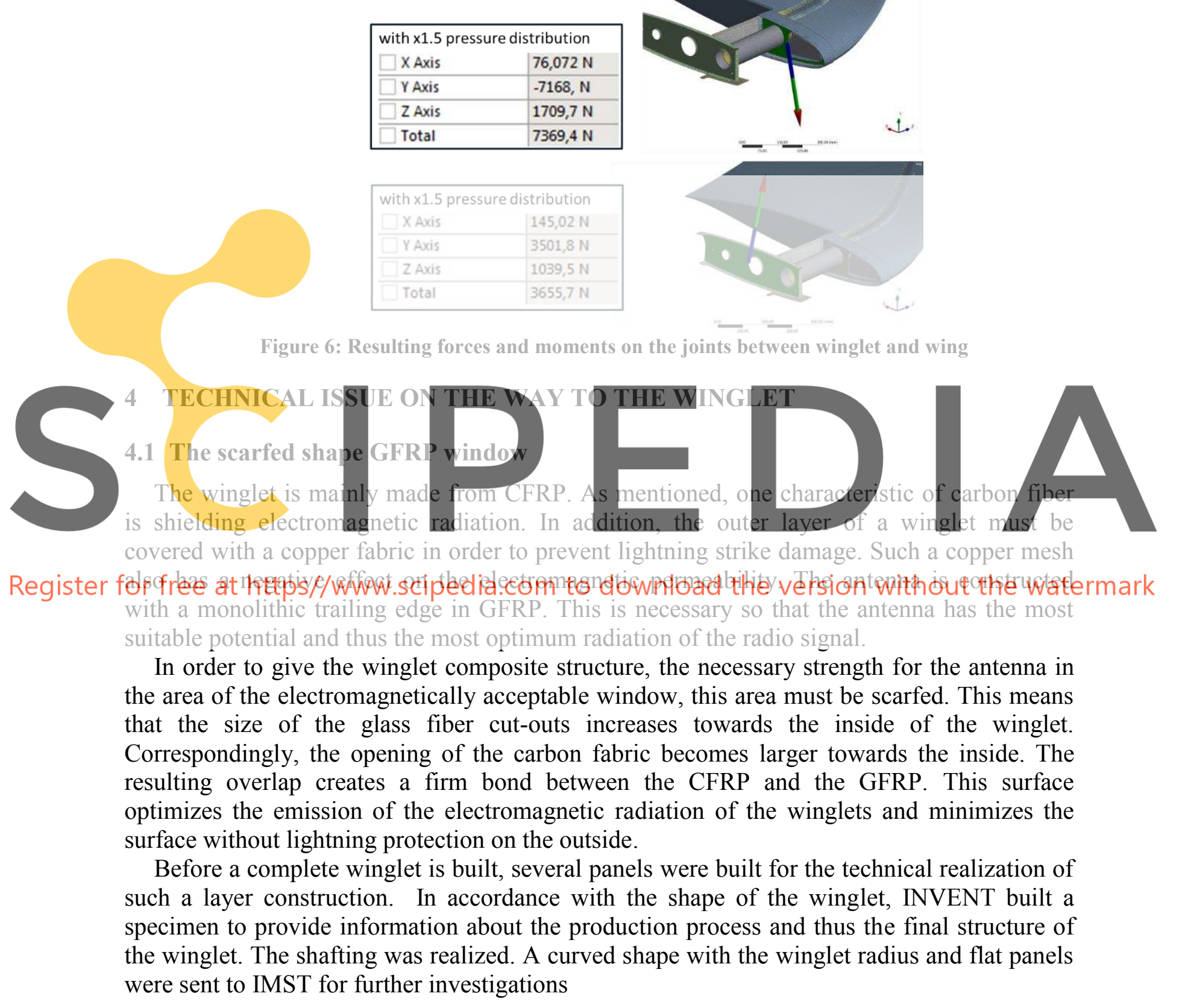


Kai Gonet, Stefan Steeger, Zdeněk Řezníček, Marta Martínez-Vásquez, Jordi Balcells-Ventura, Petr Vrchota, Victor Lungaho

\subsection{Mold construction}

The entire winglet is produced in one cycle and this has to be considered within the design process of the molds. This one cycle process production means cost-effective manufacturing, but requires a little more planning. At first, all necessary semi-finished products are prepared. The molds are wetted with a special varnish in order to release the winglet after production.

The skin layers are laid in the molds covered with a pre-impregnated resin system. A foam block milled to contour is then placed on the already prepared lower shell. This foam block also serves as a support to form the spar within the winglet. Both molds are then pressed together and cured at higher temperature by integrated heating pads.

The mold construction must be set with such precision so that the separation planes can release the winglet from the tooling negative forms after the curing of the resin. For this reason, we work with four molds. One heatable top and bottom and additionally two unheated side molds, which form the end rib facing towards the aircraft.

At first, the original forms are milled as positive (i.e. with the original contour). The negative tooling molds are then made from this positive. After preparing the milled master tooling foam, the heater mats are brought to the contour using a vacuum injection process. The necessary stability of the negative mold is then provided by applying prepreg and a specially knitted fabric (comparable to sandwich construction). Various tests must be carried out within these steps in order to document the functionality of the self-heating tools.

The geometry and the number of molds must be selected so that the molds can be separated

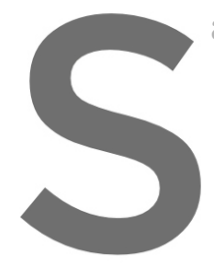
after curing. For exanp
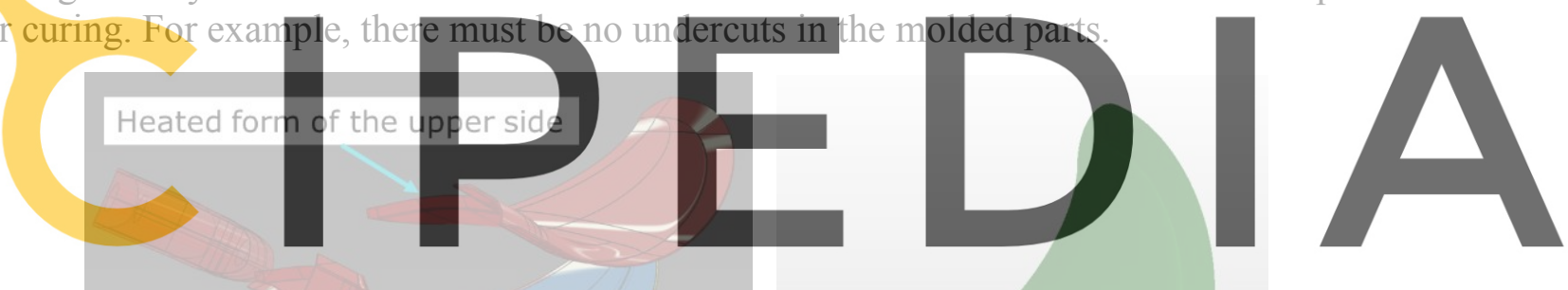

Register for free atuhtdps//www.scipedia.com to download the version without the watermark
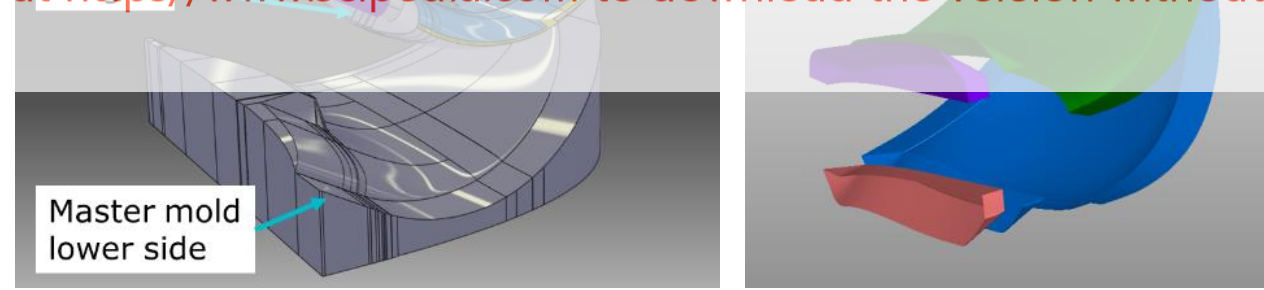

Figure 7: Left: the construction of molds and wing, Right: sepeartion area and the four mold elements for finals production process of winglet

\subsection{Heated molds}

In the ACASIAS project we are also aiming for self-heated mold production. For this purpose, it is necessary to produce special type of molds. INVENT strives for a heatable mold with specially defined heating surfaces that cure the material of the winglet at the required temperature. In this special case, we have to heat the mold up to $125^{\circ} \mathrm{C}$.

INVENT pursues two strategies for heating the molds for the winglet. At first is the possibility of placing fabric embroidered with heating wires as a layer in the negative mold. This mat is then embedded in the fiber composite. The advantage of this manufacturing 
Kai Gonet, Stefan Steeger, Zdeněk Řezníček, Marta Martínez-Vásquez, Jordi Balcells-Ventura, Petr Vrchota, Victor Lungaho

process is that the heating mat can be prefabricated exactly to the geometry needed of the produced component. The other possibility is to use a special layer of CFRP, which is connected with wiring. The internal resistance of the CFRP causes this layer to heat up. With this variant, however, the effort required for assembly is somewhat higher. The heatable surface is divided into as many large rectangular surfaces as possible. These individual surfaces must then be electrically insulated from each other using GFRP. However, the winglet has a simplified triangular shape. Various geometries were taken into consideration for optimizing several divisions of a small number of independent heating areas . These are shown in the picture. In order to save heating surface three rectangular heating surfaces are favored. In the following picture these are outlined green.

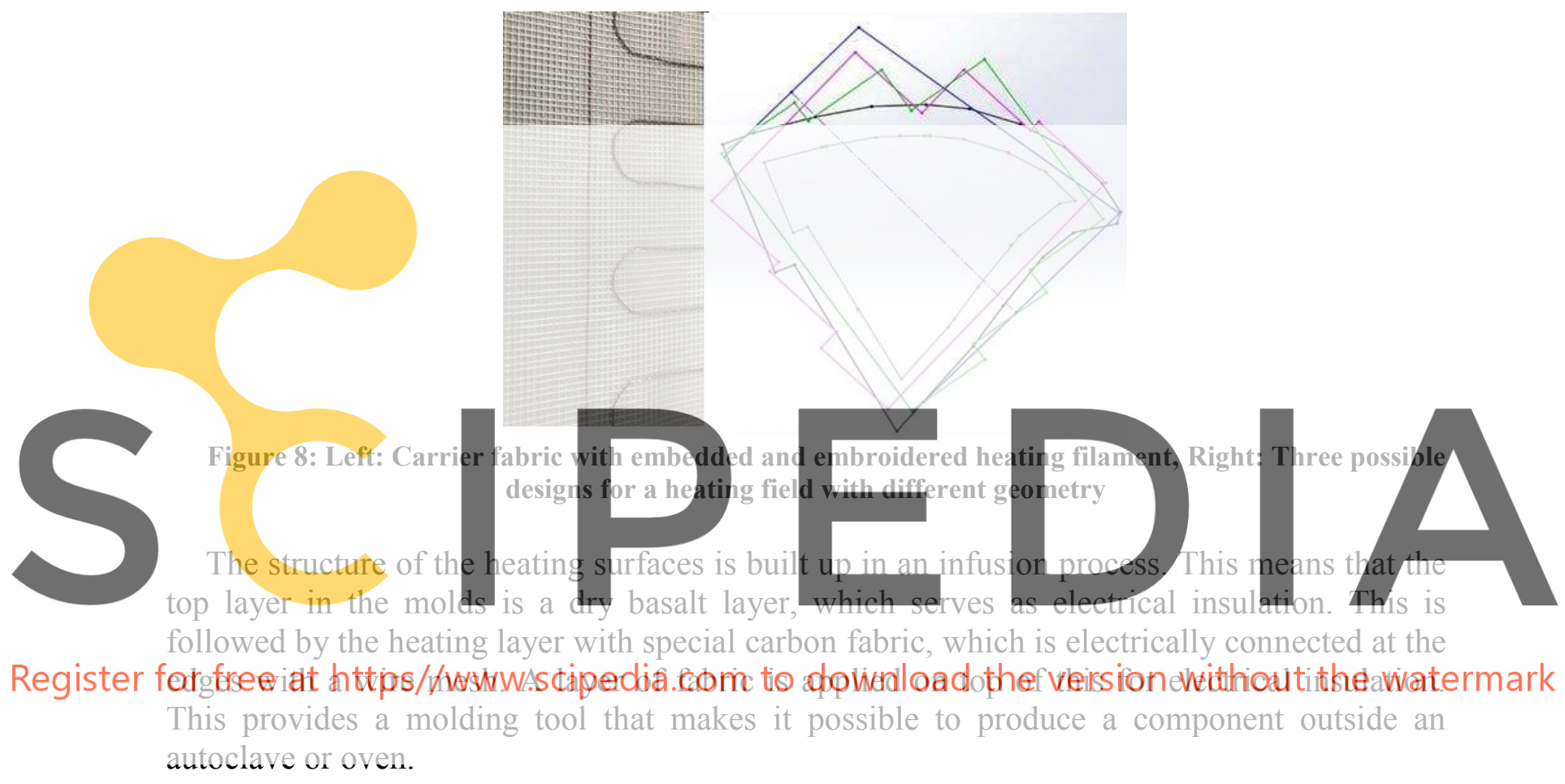

\section{MAINTENANCE AND REPAIR}

Maintenance and repair are a major focus for attention. The winglet presented here will be optimized for a smaller twin-engine 12-seater cruise aircraft. Due to the size of the aircraft, the construction volume of the winglet is very small compared to the winglet size on a large aircraft (CS-25). Due to the small construction volume and the special scarf shape GFRP flare, special repair measures are necessary.

The largest damage potential for the winglet would be: Lightning strike, collision damage, bird strike and electrically unusable/malfunction/damage antenna

For the first three types of damage, it can be assumed that the winglet would become aerodynamically and structurally unusable. This would result in a very costly repair and release to service. If the fiber composite in the area of the antenna is defective, there are different possibilities of repair. It would be possible to cut out and insert dry, large-area, prefabricated elements with the GFRP window in case of damage in the antenna area. The 
Kai Gonet, Stefan Steeger, Zdeněk Řezníček, Marta Martínez-Vásquez, Jordi Balcells-Ventura, Petr Vrchota, Victor Lungaho

scarfed flare is the biggest challenge in the production of such a patch. The ideal solution would be to replace the winglet. In the size segment of the aircraft class presented here (CS23), a new production might be cheaper than a repair.

For the repair of an electrically unusable antenna, the installation and handling space is not sufficient for the isolated repair of the antenna. Handhole covers would mean a considerable loss of the aerodynamic quality of the winglet for an aircraft of this size. One way to repair the antenna within the winglet would be to use position lights and ACL (Anti Collision Light) for opening the antenna mounting surface from the front of the winglet. For the best possibility of maintenance for the antenna would be a mounting, in which the flexible material could be slid into the final position.

The focus for the endurance tests should be a program for the durability of the solder joint for the antenna. The antenna is produced by TRACKWISE. There, the solder joints could also be made of flexible material and integrated into the manufacturing process of the antenna. The worst case for an electrical failure would be a cable break close to an edge near the wing root or a hidden cable break. These faults should be tested in a fatigue strength test and should lead separately to a special repair instruction.

For larger aircraft there are more possibilities to position the antenna with regard for a cheaper repair of the antenna itself. Unfortunately, the construction of the antenna depends on the fact that the flare must have a glass fiber edge at the end. Nevertheless, it would be possible to reach the antenna through an opening of the Leading Edge (through the holder of

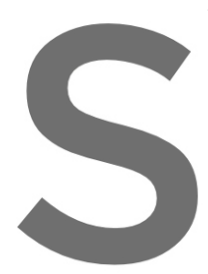
the position lights) by
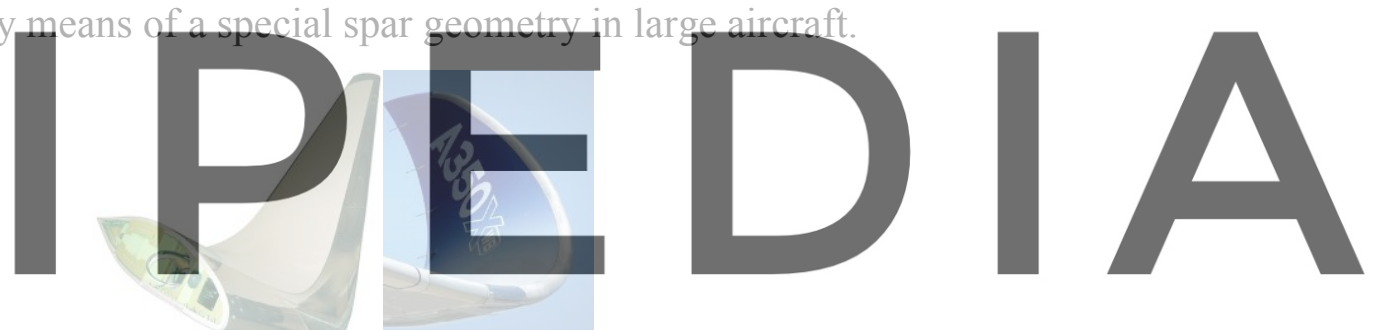

Register for free at https//www.scipedia.com to download the version without the watermark Figure 9: Two different winglets with position lights and openings for possible antenna replacement (from internet picture research [10] and [11])

\section{CONCLUSION AND OUTLOOK}

The first results of the integration of a VHF notch antenna in an aircraft winglet have been presented. The antenna measured performance complies with the requirements in terms of bandwidth. The next steps include the measurement of the radiation patterns, and the adaption of the structure to the real, conformal winglet geometry.

Lightning protection will also be investigated in this context. Since the winglet is the component predestined for lightning strikes, this issue will be investigated further more. Especially with regard to the electrical components inside the winglet, it is necessary to discuss the rules and regulation for the certification and for increasing the TRLs.

\section{ACKNOWLEDGEMENTS}

All work described in this paper has received funding from the European Union's Horizon 2020 research and innovation programme under grant agreement No 723167, ACASIAS project. 
Kai Gonet, Stefan Steeger, Zdeněk Řezníček, Marta Martínez-Vásquez, Jordi Balcells-Ventura, Petr Vrchota, Victor Lungaho

\section{REFERENCES}

[1] "Advanced Concepts for Aero Structures with Integrated Antennas and Sensors", http://www.acasias-project.eu/

[2] J. Verpoorte, "Requirements and Specification Document", ACASIAS Deliverable 1.1, [online].

[3] Z. Reznicek, Towards Multi-objective Design of EV55 Winglet with integrated VHF antenna, EMUS2019, Barcelona

[4] Marta Martinez-Vásquez, Jord Balcells-Ventura, „VHF notch antenna integrated in an aircraft winglet", EMUS2019, Barcelona

[5] P. Vrchota, S. Steeger, M. Martinez-Vazquez, M. Svetlik, Z. Reznicek, "Aerodynamic and structural design of winglet with integrated VHF antenna", 8th EASN-CEAS Int. Workshop on Manufacturing for Growth \& Innovation, 2018, Available: https://doi.org/10.1051/matecconf/201823300018

[6] R.A. Burberry, "VHF and UHF antennas", IEE Electromagnetic series 36, Peter Peregrinus, 1992.

[7] Empire XPU Manual, 2016, [online].

[8] CST, "Electromagnetic Simulation of Composite Materials and Cable Harnesses in Aircraft", [online].

[9] Elliot J. Riley, Erik H. Lenzing, Ram M. Narayanan, "Characterisation of carbon fiber composite materials for RF applications", Proc. Of SPIE, May 2014, DOI:

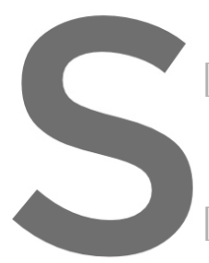
$10.1117 / 12.2050132$

10] Dieter Scholz, Aircraft Design a Berliner Tor 9, 20099 Hamburg, Cerman 11] https://aegistg.com/how-the-59-caddy-sav
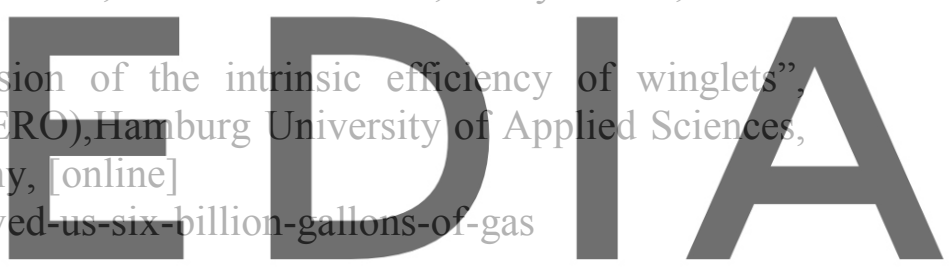

Register for free at https//www.scipedia.com to download the version without the watermark 